\title{
Intra-articular primatised anti-CD4: efficacy in resistant rheumatoid knees. A study of combined arthroscopy, magnetic resonance imaging, and histology
}

D J Veale, R J Reece, W Parsons, A Radjenovic, P J O'Connor, C S Orgles, E Berry, J P Ridgway, U Mason, A W Boylston, W Gibbon, P Emery
Rheumatology and

Rehabilitation

Research Unit

D J Veale

R J Reece

W Parsons

P Emery

Centre of Medical Imaging Research A Radjenovic

P J O'Connor

C S Orgles

E Berry

J P Ridgway

W Gibbon

and Department of Molecular Medicine A W Boylston

University of Leeds, Leeds

SmithKline Beecham

Pharmaceuticals

U Mason

Correspondence to: Professor P Emery, 36 Clarendon Road, Leeds LS3 9NZ.

Accepted for publication 10 February 1999

\begin{abstract}
Objectives-CD4+ $T$ cells sustain the chronic synovial inflammatory response in rheumatoid arthritis (RA). SB210396/CE 9.1 is an anti-CD4 monoclonal antibody that has documented efficacy in RA when given intravenously. This study aimed to establish the safety and efficacy of the intra-articular administration of SB-210396/CE 9.1 compared with placebo, examining its mode of action using a combined imaging approach of arthroscopy, magnetic resonance imaging (MRI), and histology.
\end{abstract}

Methods-Thirteen RA patients with active, resistant knee synovitis, were randomised to intra-articular injection of placebo $(\mathrm{n}=3), 0.4 \mathrm{mg}(\mathrm{n}=3)$ or $40 \mathrm{mg}$ $(n=7)$ of anti-CD4 after sequential dynamic gadolinium enhanced MRI, followed by same day arthroscopy and synovial membrane biopsy. Imaging and arthroscopic synovial membrane sampling were repeated at six weeks. This study used a unique region of interest (ROI) analysis mapping the MRI area analysed to the specific biopsy site identified arthroscopically, thus providing data for all three modalities at the same synovial membrane site.

Results-12 patients completed the study (one placebo treated patient refused further MRI). Arthroscopic improvement was observed in 0 of 2 placebo patients but in 10 of 10 patients receiving active drug (>20\% in 6 of 10). Improvement in MRI was consistently observed in all patients of the $40 \mathrm{mg}$ group but not in the other two groups. A reduction in SM CD4+ score was noted in the $40 \mathrm{mg}$ group and in the $0.4 \mathrm{mg}$ group. Strong correlations both before and after treatment, were identified between the three imaging modalities. Intra-articular delivery of SB-210396/CE 9.1 was well tolerated.

Conclusions-SB-210396/CE 9.1 is safe when administered by intra-articular injection. A trend toward efficacy was found by coordinated MRI, arthroscopic, and histological imaging, not seen in the placebo group. The value of ROI analysis was demonstrated.

(Ann Rheum Dis 1999;58:342-349)
Rheumatoid arthritis (RA) is a chronic symmetrical polyarthritis characterised by persistent inflammation of the synovial membrane (SM) with characteristic mononuclear cell infiltration and lining layer hyperplasia. CD4+ $\mathrm{T}$ lymphocytes are believed to be important in RA SM interacting with other inflammatory cells including macrophages, synovial fibroblasts, and plasma cells. ${ }^{1}$ This role is supported by evidence that lymphocyte depletion, by thoracic duct drainage, total body irradiation or pharmacological manipulation is clinically efficacious in established RA. ${ }^{2-4}$

A number of monoclonal antibodies (MAbs) directed against $\mathrm{T}$ cells have been administered in RA..$^{5-16}$ Initially, murine and subsequently chimeric MAbs were delivered by the intravenous route. A recent review highlighted open studies demonstrating efficacy ${ }^{5-11}$ while double blind studies have been less convincing. ${ }^{11}{ }^{12}{ }^{15} \mathrm{~A}$ further study demonstrated a reduction in infiltrating $\mathrm{T}$ cells without clinical efficacy, ${ }^{16}$ suggesting that alternative mechanisms may also be important. Thus, doubts about the role of anti-CD 4 have arisen, compounded by the absence of any objective measure of outcome, ${ }^{17}$ particularly as the acute phase response is not directly affected by anti-CD 4 treatment.

The mainstay of treatment of inflamed joints is intra-articular (IA) injection of corticosteroids, benefit from which may be sustained for

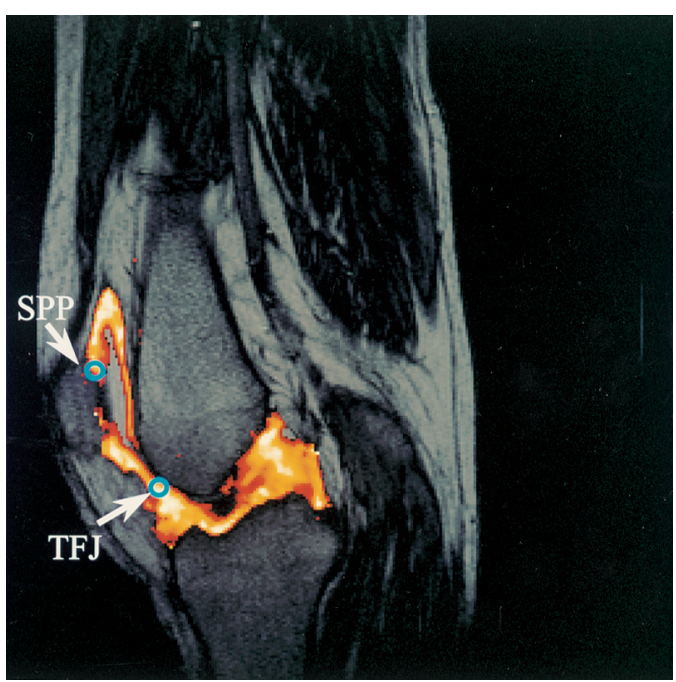

Figure 1 Magnetic resonance image of the knee joint. This demonstrates a typical dynamic $T 1$ weighted gradient echo magnetic resonance image (TR/TE/flip angle $30 / 12 / 60^{\circ}$ ) used to map with the computer localised regions of interest $\left(\right.$ area $=11.8 \mathrm{~mm}^{2}$ ) at the suprapatellar pouch (SPP) and the tibiofemoral joint (TFF). 
Table 1 Patient characteristics by treatment group for study completers

\begin{tabular}{|c|c|c|c|}
\hline Parameter & $0.4 \mathrm{mg}$ & $40 \mathrm{mg}$ & placebo \\
\hline Patients (n) & 3 & 7 & 2 \\
\hline Female:male & $2: 1$ & $6: 1$ & $1: 1$ \\
\hline Median age in years (range) & $72.3(70-76)$ & $62.6(36-72)$ & $68.0(63-73)$ \\
\hline $\begin{array}{l}\text { Median disease duration in years } \\
\text { (range) }\end{array}$ & $11.3(1-22)$ & $114(3-20)$ & $133(8-17)$ \\
\hline Current DMARD use & 3 & 6 & 2 \\
\hline Methotrexate & 1 & 4 & 1 \\
\hline Sulphasalazine & 0 & 2 & 1 \\
\hline Azathioprine & 1 & 0 & 0 \\
\hline Cyclosporin & 1 & 0 & 0 \\
\hline Current prednisolone use & 1 & 1 & 1 \\
\hline $\begin{array}{l}\text { Baseline median knee circumference } \\
\quad(\mathrm{cm}) \text { (range) }\end{array}$ & $38.6(37.6-39.5)$. & $36.5(36.1-38.9)$ & $38.2(35.4-41.0)$ \\
\hline $\begin{array}{l}\text { End median knee circumference }(\mathrm{cm}) \\
\text { (range) }\end{array}$ & $38.4(35.8-41.0)$ & $37.1(35.8-40.1)$ & $38.6(35.4-41.8)$ \\
\hline Baseline median CRP (g/dl) (range) & $8.5(3.4-45.1)$ & $27.5(6.2-79.6)$ & $66.1(40.1-92.0)$ \\
\hline End median CRP (g/dl) (range) & $35.4(15.0-52.2)$ & $24.0(8.4-102)$ & $50.2(8.4-92.0)$ \\
\hline $\begin{array}{l}\text { Intra-articular corticosteroid } \\
\text { requirement at } 18 \text { months follow up }\end{array}$ & (2) (20) & - & 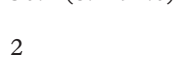 \\
\hline
\end{tabular}

considerable periods. However, in certain cases relative resistance to such local treatment may develop. In such patients there is a need for an effective local treatment and such joints are suitable not only for novel interventions but are accessible for imaging thus offering the opportunity for definitive study of mode of action.

Conventional imaging of the joints, and histological examination of biopsy specimens from arthroscopy or a closed needle technique (Parker-Pearson needle), have previously been attempted, however limitations were noted. ${ }^{18} 19$ Needle arthroscopy is a safe and patient tolerable procedure permitting direct visualisation and biopsy of a specific region of interest (ROI) and semi-quantitative histological measures are well established. ${ }^{20}{ }^{21}$ Magnetic resonance imaging (MRI) provides high quality digital images that can define cartilage and subchondral bone without exposure to ionising radiation. $^{22} 23$ Its diagnostic capabilities have been compared with needle arthroscopy in the knee. ${ }^{24}$ Furthermore, the extent of synovial disease can be measured by scanning dynamically after the contrast administration. Quantitative analysis of dynamic Gd-DPTA enhanced MRI (DEMRI) can provide a measure of blood perfusion, capillary permeability, and extracellular volume all of which characterise the inflammatory process. ${ }^{18} 1925-27$

SB-210396/CE 9.1 is a chimeric primatised anti-CD $4 \mathrm{MAb}$, which is currently in phase III development by SmithKline Beecham and IDEC Pharmaceuticals. A large repeat dose, placebo controlled study of intravenous SB210396/CE 9.1 has shown significant efficacy compared with placebo. ${ }^{28}$ SB-210396/CE 9.1 has not previously been administered by IA injection. This study examined the efficacy of a single IA injection of MAb using a coordinated imaging approach in resistant knee synovitis.

\section{Methods}

Thirteen RA patients (1987 American College of Rheumatology criteria) attending the Rheumatology clinic at Leeds General Infirmary, with active synovitis of the knee (pain, tenderness, effusion) that had proved resistant $(<2$ weeks improvement) to at least two IA corticosteroid injections were enrolled into this study. The study was approved by the local research ethics committee and written informed consent obtained from all subjects. All patients were receiving stable doses $(>3$ months) of oral medication: seven methotrexate, two sulphasalazine, one cyclosporin, one azathioprine; seven patients were receiving non-steroidal anti-inflammatory drugs and two subjects oral corticosteroids ( $<10 \mathrm{mg}$ daily).

\section{STUDY DESIGN}

Patients were assessed on day -7 , day 0 (dosing day), and days 3, 14, and 42 (study end). Clinical assessments by a single observer (RR), included measurement of knee circumference at midpoint of patella and physician assessment of disease activity in the signal knee. This was followed immediately by sequential imaging with dynamic Gd-DPTA enhanced MRI (DEMRI), followed within two hours by arthroscopy and synovial biopsy. Immediately after the arthroscopy $10 \mathrm{ml}$ of SB-210396/CE 9.1 or placebo was administered by slow IA injection at the tibiofemoral portal site. The physician performing the clinical assessment and giving the IA injection was blinded to the treatment and test results. Laboratory assessments including full blood count, biochemical profile, and $\mathrm{C}$ reactive protein were carried out at each imaging visit, and all investigations including DEMRI, arthroscopy and biopsy were repeated on day 42 .

MRI

All MRI knee examinations were performed on a $1.5 \mathrm{~T}$ Gyroscan ACS NT MR (Philips Medical Systems, the Netherlands) equipped with a quadrature knee coil. Patients were positioned supine with the signal knee placed within the knee coil and held in extension in the neutral position. After an initial localising scan multiple coronal and axial $\mathrm{T} 1$ weighted images were obtained to provide anatomical landmarks in the suprapatellar pouch (SPP) and tibiofemoral joint (TFJ), which were used to define a reproducible sagittal plane for quantitative measurements. This was perpendicular to two planes joining both the most (a) posterior margins localised axially, and (b) inferior margins localised coronally, of the femoral condyles. The quantitative measurements were derived from a dynamic $\mathrm{T} 1$ weighted gradient echo imaging sequence (TR/TE/flip angle $30 / 12 / 60^{\circ}$ ), which allowed the acquisition of $5 \mathrm{~mm}$ thick images every five seconds for a period of 200 seconds. Administration of Gd-DPTA was performed immediately after the first image of the series was obtained. ${ }^{26}$ Image analysis was performed using the Analyze biomedical image processing package ${ }^{29}$ and specially developed inhouse software. Two measurements of synovial disease activity were obtained using (a) magnitude and rate of Gd-DTPA uptake (b) enhancing synovial volume. Two regions of interest (ROI), $11.8 \mathrm{~mm}^{2}$ in area, were subsequently selected by the arthroscopist to correspond with the SPP and TFJ biopsy sites (fig 1). Signal intensity (SI) curves were obtained from the ROIs for the entire series of dynamic images and normalised with respect to the 

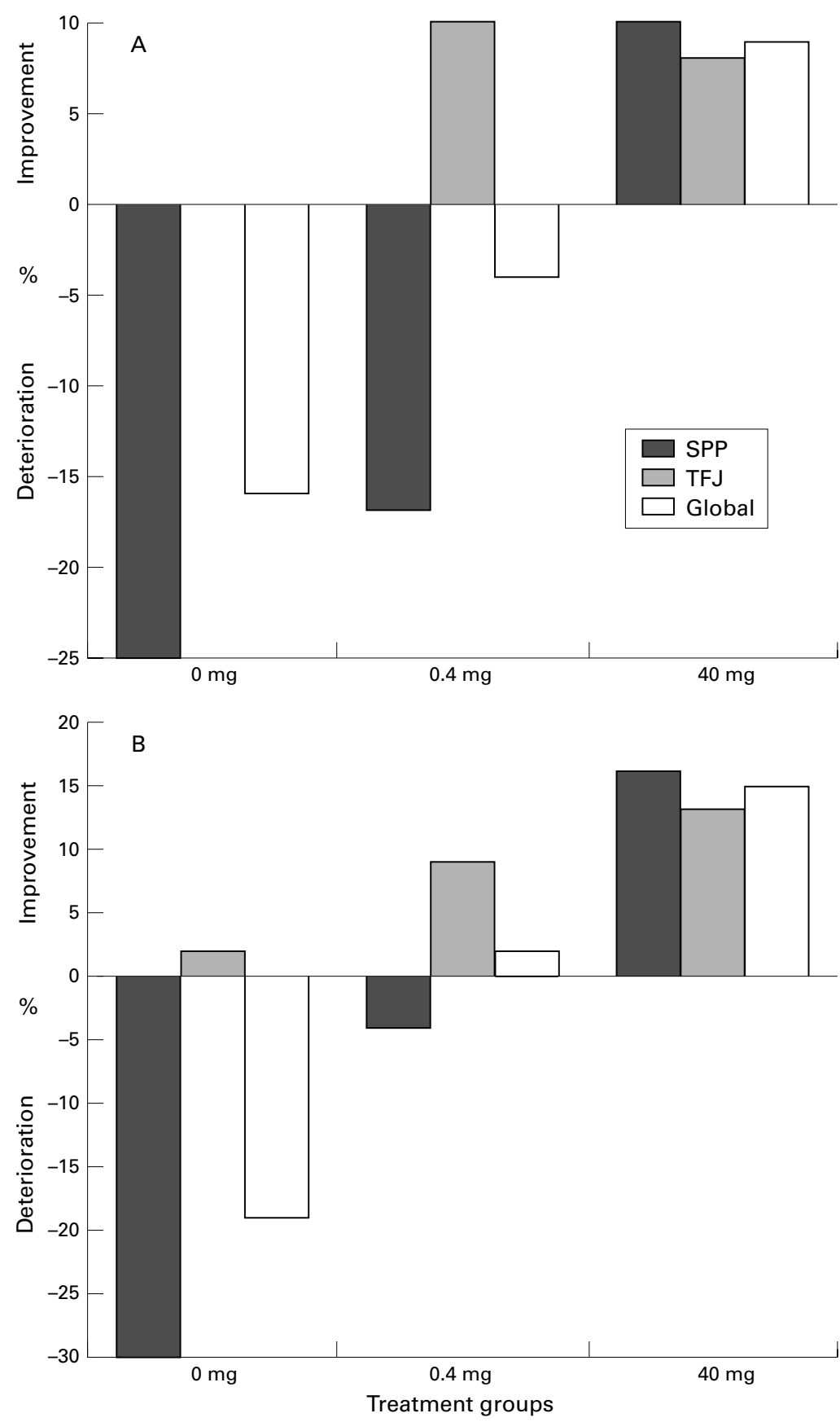

Figure 2 The percentage change of median dynamic enhanced (Gadolinium-DTPA) magnetic resonance imaging parameters over baseline with respect to: $(A)$ maximum rate of normalised signal intensity enhancement (MRE) reflecting synovial capillary permeability; and $(B)$ the maximum normalised signal intensity enhancement (ME) reflecting the perfusion and the volume of the extracellular fluid at the regions of interest and globally in the three treatment groups. (A) Deterioration in MRE is seen at both regions and globally in the placebo group. Ten per cent improvement is seen only at the tibiofemoral joint region in the $0.4 \mathrm{mg}$ group. Improvement (up to $10 \%$ ) is seen at both regions of interest and globally in the group treated with $40 \mathrm{mg}$ of active drug. (B) Deterioration is seen at the suprapatellar region and globally in the placebo group. Mild improvement $(<10 \%)$ is seen at the tibiofemoral joint region and globally in the $0.4 \mathrm{mg}$ group. Improvement $(10-20 \%)$ is seen at both regions of interest and globally in the group treated with $40 \mathrm{mg}$ of active drug.

baseline (pre-contrast) SI. The maximal rate of SI enhancement (MRE) and the maximum SI enhancement (ME) was then calculated. A measure of the volume of enhancing synovial membrane was obtained by counting the pixels with greater than $50 \%$ ME. For each variable, the median value for the set of ROIs was found and the percentage change after treatment was then calculated. These changes were compared with the clinical and the arthroscopic findings.
ARTHROSCOPY AND SYNOVIAL BIOPSY

Needle arthroscopy with local anaesthetic (1\% prilocaine) was performed immediately after MRI on days 0 and 42 at the day case unit, Chapel Allerton Hospital, Leeds. A Storz 2.7 $\mathrm{mm}$ diameter $/ 30 \% 13 \mathrm{~cm}$ long arthroscope was introduced through standard portals. Images from an Endovision camera, using an halogen light source, were displayed on a 14" Sony colour monitor. The arthroscopic findings and SM sampling sites were reported on a graphic assessment form and recorded on super-VHS videotape. Systematic inspection of the SPP and TFJ compartments was performed, grading hyperaemia $(0-1)$, granulation $(0-1)$ or villous hypertrophy (0-2). In addition, an overall impression of the synovial inflammation was recorded on a $100 \mathrm{~mm}$ visual analogue scale. Synovial biopsy specimens $\left(4-6 \mathrm{~mm}^{2}\right.$ in size) from sites in the sagittal plane corresponding to that used for MRI acquisition and to represent maximal and minimal inflammation were taken under direct vision using biopsy forceps. Joint irrigation was completed to a minimum of $1000 \mathrm{ml} 0.9 \%$ saline and $10 \mathrm{ml}$ of study drug or placebo was then slowly injected into the knee. The wounds were dressed with Steristrips and Primapore and crepe bandage applied for 24 hours. The patients were rested and observed for 60 minutes before discharge home. The post-treatment arthroscopy was conducted identically with repeat SM sampling from synovium within the imaging axis, immediately adjacent to the sites of pre-treatment biopsy.

\section{IMMUNOHISTOLOGY}

One biopsy specimen from each site was fixed in $10 \%$ formaldehyde for conventional histological preparation with haemotoxylin and eosin, and one sample from each site was embedded in Bright's OCT, snap frozen at $-70^{\circ} \mathrm{C}$ and stored in a refrigerator at $-80^{\circ} \mathrm{C}$ until sectioned. Serial sections $5 \mu \mathrm{m}$ thick were cut, mounted on glass slides, fixed in acetone at room temperature, and air dried. A routine three stage immunoperoxidase staining technique was used with monoclonal antibodies to CD3, CD4 (OKT4), CD8, CD20, CD68, and $\mathrm{MHC}$ class II. Incubations were carried out at room temperature, primary antisera were diluted in phosphate buffered serum (PBS) with $1 \%$ (weight/volume) bovine serum albumin (BSA). The horseradish peroxidase (HRP) conjugated antibodies were diluted in $1 \%$ PBS-BSA with $10 \%$ (volume/volume) normal human serum as blocking serum. Endogenous peroxidase activity was inhibited using $0.1 \%$ sodium azide and $0.3 \%$ hydrogen peroxide in PBS. All sections were scored independently by two observers (AWB and DJV), before the study was unblinded, using a recognised 5 point scale for semiquantitative scoring, ${ }^{16}$ a score of $0=$ minimal infiltration, a score of $4=$ numerous inflammatory cells. In addition, each SM sample was assigned a score for lining layer hyperplasia $(\mathrm{LLH})(0=1-2$ cell layers, $1=3-4$ cell layers, $2=5-6$ cell layers, $3=\geqslant 7$ cell layers). Positive and negative staining controls were used throughout. 


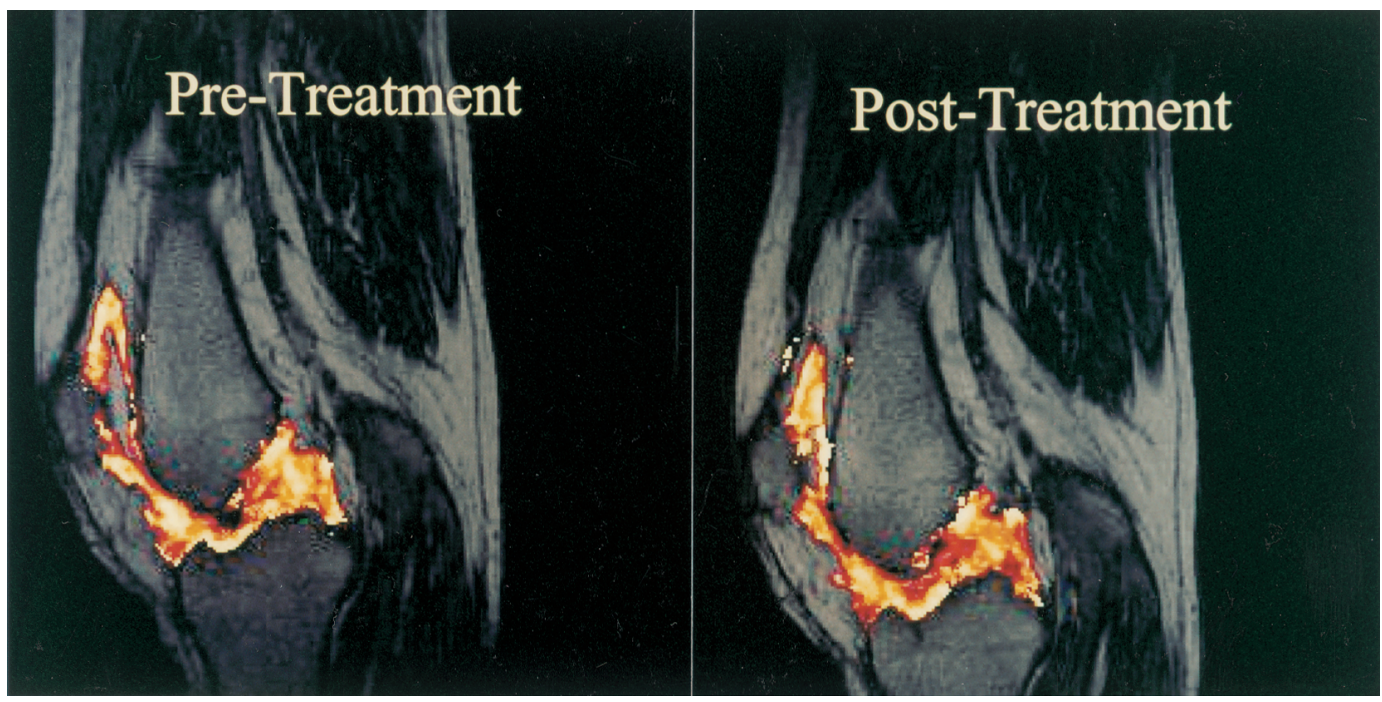

Figure 3 Quantitative maps of gadolinium-DTPA magnetic resonance images of the knee joint pre-and post-treatment with SB-210396. The images show the difference in maximal rate of signal intensity enhancement (sec ${ }^{-1}$ ) before and after treatment of one patient from the $40 \mathrm{mg}$ treatment group. The scale ranges from minimum $=0.016$ (red) to maximum $=$ 0.88 (yellow). The pre-treatment image is predominantly yellow indicating a high maximal rate of enhancement while in contrast, the post-treatment image shows more red reflecting a reduced rate of enhancement .

\section{STATISTICS}

In view of the small numbers of patients in each group median values were calculated for all imaging parameters, differences before and after were examined using Wilcoxon paired test and correlations with the Spearman rank test. Significance was defined at the $\mathrm{p} \leqslant 0.05$ level.

\section{Results}

There were three male and 10 female subjects aged between 35-76 years (mean 66) with a mean disease duration of 12.4 years (range 2-29). Twelve patients were seropositive for rheumatoid factor. One placebo group patient did not complete the study because of refusal to undergo follow up MRI resulting from claustrophobia. The patients in the low dose treatment group had a higher mean age than the other groups, however disease duration was comparable. One patient in each active treatment group was receiving oral prednisolone treatment and only one participant (in the 40 mg cohort) was not receiving concomitant DMARD treatment. One patient receiving placebo and three receiving $40 \mathrm{mg}$ active drug experienced injection site pain, however no

Table 2 Arthroscopic VAS assessments ( $\mathrm{mm}$ ), observer scoring overall synovitis before and after dosing with intra-articular primatised anti-CD4 monoclonal antibody

\begin{tabular}{clllc}
\hline \multicolumn{1}{c}{} & $\begin{array}{l}\text { Arthroscopic } \\
\text { VAS for } \\
\text { synovitis } \\
\text { before dose }\end{array}$ & $\begin{array}{l}\text { Arthroscopic } \\
\text { VAS for } \\
\text { synovitis } \\
\text { after dose }\end{array}$ & $\begin{array}{l}\text { Difference } \\
\text { in scores }\end{array}$ \\
\hline $\begin{array}{c}\text { Treatment } \\
\text { groups }\end{array}$ & Placebo & 69 & 76 & 7 \\
& $0 \mathrm{mg}$ & 67 & 70 & -3 \\
& median & 68 & 73 & -5 \\
& $0.4 \mathrm{mg}$ & 64 & 60 & 4 \\
& 86 & 48 & 38 \\
& & 64 & 37 & 27 \\
& median & 64 & 48 & 27 \\
& $40 \mathrm{mg}$ & 89 & 71 & 28 \\
& 80 & 58 & 22 \\
& 76 & 47 & 29 \\
& 93 & 41 & 52 \\
& 77 & 63 & 14 \\
& 83 & 73 & 10 \\
& & 71 & 61 & 10 \\
& & & & \\
\hline
\end{tabular}

serious adverse events were recorded with follow up at 18 months. No significant difference was observed in knee circumference or acute phase protein response. The mean C reactive protein $(\mathrm{g} / \mathrm{dl})$ showed no significant improvement in any group over the study. In addition, no statistically significant improvement was observed in the knee circumference or physician assessment of knee synovitis over the study period, although the latter showed a slight improvement in all seven patients who received high dose treatment. Clinical follow up now extends to 18 months in this group and nine patients have not required any further local injection therapy in this period (table 1).

\section{ARTHROSCOPY}

Table 1 shows the arthroscopic scores for synovitis as measured with the VAS before and after treatment. The VAS for synovitis deteriorated in the two placebo patients while the actual scores and the median values in all patients receiving active treatment showed an improvement. Taking improvement of $20 \%$ or more as significant, two of three patients receiving $0.4 \mathrm{mg}$ and four of seven of the $40 \mathrm{mg}$ group reached this level. Analysis of the median improvement in the treated patients overall showed there was a $27 \mathrm{~mm}(42 \%)$ and $22 \mathrm{~mm}$ $(27 \%)$ change in the $0.4 \mathrm{mg}$ and the $40 \mathrm{mg}$ group respectively. Synovial inflammation was also subjectively graded according to a number of visual features including granularity, vascularity, and villous hypertrophy. There was no significant trend in this assessment between the patient groups or in relation to treatment.

MRI

Patients receiving placebo showed no improvement in MRE, \% change in median from baseline to end of study, in either ROI or the global score for the (fig 2A). In contrast, improvement in MRE was found at the TFJ in the patients receiving $0.4 \mathrm{mg}$ dose, although a deterioration was noted at the SPP ROI. The $40 \mathrm{mg}$ dose group, demonstrated up to $10 \%$ improvement 

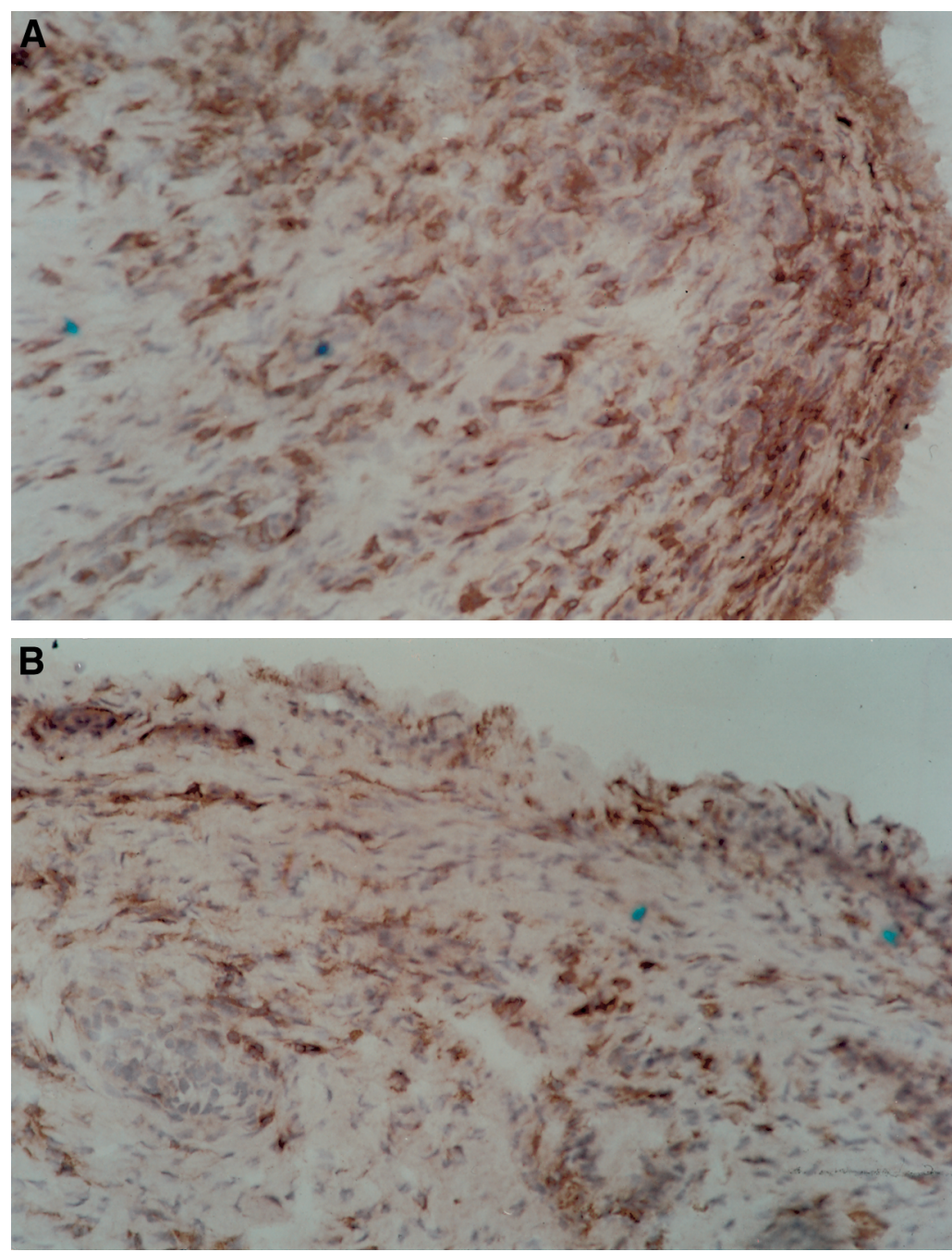

Figure 4 Photomicrographs of the synovial membrane before and after treatment. Immunoperoxidase staining with an anti-CD4 monoclonal antibody (OKT4), of a patient who received $40 \mathrm{mg}$ active drug. (A) Synovial tissue before treatment shows staining of numerous CD4 + cells. (B) Synovial tissue after treatment from the same patient showing marked reduction of CD4+ cells.

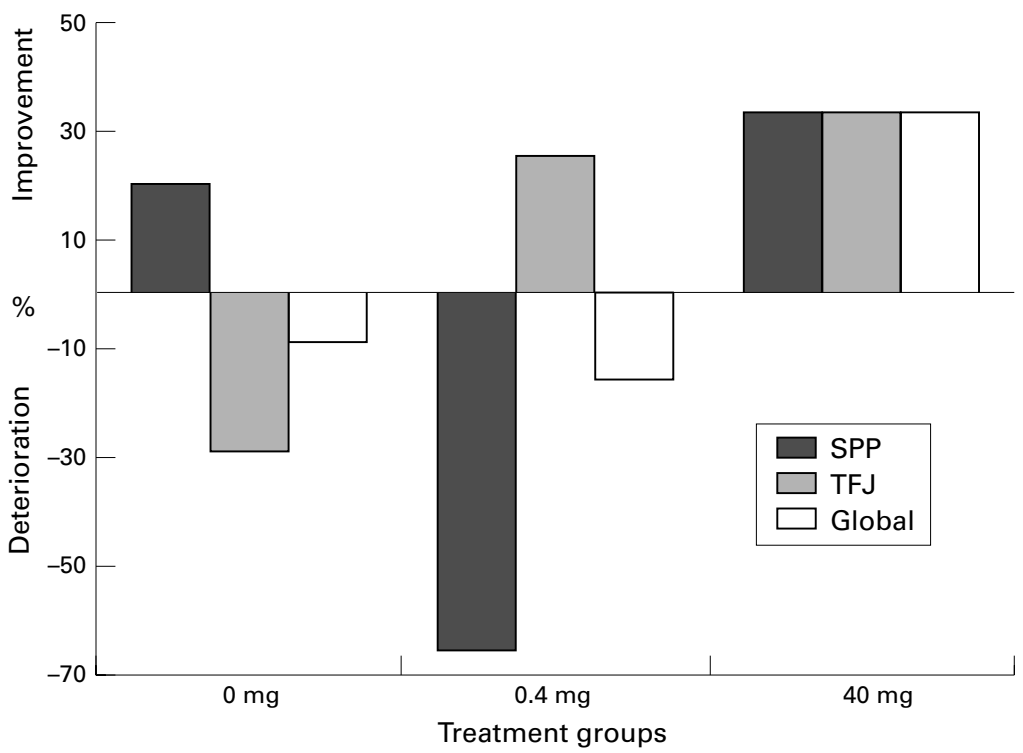

Figure 5 Percentage change in the median CD4 scores. This graph shows change from baseline in immunohistological CD4 scores at the regions of interest and globally, for the three treatment groups. Improvement (>30\%) was seen at all sites in the $40 \mathrm{mg}$ group. Improvement was also seen at the tibiofemoral joint region in the $0.4 \mathrm{mg}$ group and at the suprapatellar region in the placebo group. of MRE at the SPP and the TFJ (fig 2A and fig 3). On analysis of a global score representing the change in MRE at both ROIs in the three groups there was a dose response effect, although this did not reach statistical signifcance.

A change in $\mathrm{ME}$ before and after treatment was seen in patients who received active drug. The \% change in median ME (fig 2B), showed a similar pattern to the change in MRE, with improvement at both ROIs (globally) seen only in those patients receiving the high dose while the $0.4 \mathrm{mg}$ group showed a small response at the TFJ ROI but not at the SPP ROI. In the 40 $\mathrm{mg}$ group, ME at the TFJ improved by $17.6 \%$ and at the SPP ROI by $16 \%$ over the study period. The synovial volume measurements did not change significantly over the course of the study.

\section{HISTOLOGICAL ASSESSMENT}

There was an increase in the median scores for SM lining layer hyperplasia and CD4 cells in both placebo patients during the study (table 2). In contrast, the lining layer score showed a decrease in both treatment groups. This was most marked in the low dose group, in which two of three patients showed a noticeable improvement followed by the $40 \mathrm{mg}$ dose group, in which five of seven patients either showed no change or a slight improvement. The immunohistological staining showed changes in the CD4 score with improvement in the active groups before (fig 4A) and after (fig $4 \mathrm{~B})$ treatment while the placebo group deteriorated. Overall, the global CD4 score showed a reduction by $30 \%$, representing an improvement in the group who received $40 \mathrm{mg}$ of active drug while increases of $15 \%$ and $10 \%$ were seen in the $0.4 \mathrm{mg}$ group and in the placebo group, respectively (fig 5). Analysis of CD3, CD8, CD20, CD68, MHC class II revealed no significant change.

Immunophenotyping of peripheral blood lymphocytes performed at baseline and repeated at the end of the study showed a marginal reduction in numbers of circulating CD3+/CD4+/CD8- cells in both treatment groups and a rise in the placebo group (data not shown).

CORRELATIONS BETWEEN IMAGING TECHNIQUES Several statistically significant correlations were observed in this study between the imaging modalities examined and these held true across both time points (table 3). The most significant correlations were observed between the MRE at the SPP ROI and the arthroscopic VAS for synovitis $(r=0.77 ; \mathrm{p}=0.003)$ and between the MRE and immunohistological CD4 score, globally $(r=0.70 ; \mathrm{p}=0.011)$. Significant correlations were also seen between the arthroscopic VAS for synovitis and the histological SM LLH global score $(r=0.59$; $\mathrm{p}=0.042$ ), which in turn also correlated with the CD4 global score. These correlations were calculated for the ROIs selected at arthroscopy, biopsied under direct visual inspection and subsequently mapped on to the MR image. 
Table 3 Global CD4 counts and lining layer hyperplasia scores before and after dosing with intra-articular primatised anti-CD4 monoclonal antibody

\begin{tabular}{|c|c|c|c|c|c|c|c|}
\hline Global & & $\begin{array}{l}\text { CD4 } \\
\text { before } \\
\text { dose }\end{array}$ & $\begin{array}{l}\text { CD4 } \\
\text { after } \\
\text { dose }\end{array}$ & $\begin{array}{l}\text { Difference } \\
\text { in scores }\end{array}$ & $\begin{array}{l}\text { Hyperplasia } \\
\text { before dose }\end{array}$ & $\begin{array}{l}\text { Hyperplasia } \\
\text { after dose }\end{array}$ & $\begin{array}{l}\text { Difference } \\
\text { in scores }\end{array}$ \\
\hline Treatment groups & $\begin{array}{l}0 \mathrm{mg} \\
\text { Median } \\
0.4 \mathrm{mg} \\
\text { Median } \\
40 \mathrm{mg}\end{array}$ & $\begin{array}{l}7 \\
3 \\
5 \\
2 \\
8 \\
4 \\
4 \\
6 \\
6 \\
1 \\
8 \\
5 \\
7 \\
2 \\
6\end{array}$ & $\begin{array}{l}8 \\
3 \\
5.5 \\
1 \\
6 \\
7 \\
6 \\
8 \\
3 \\
0 \\
6 \\
3 \\
4 \\
3 \\
3\end{array}$ & $\begin{array}{c}-1 \\
0 \\
-0.5 \\
1 \\
2 \\
-3 \\
-2 \\
-2 \\
3 \\
1 \\
2 \\
2 \\
3 \\
-1 \\
3\end{array}$ & $\begin{array}{l}2 \\
0 \\
1 \\
4 \\
5 \\
2.5 \\
4 \\
6 \\
4 \\
3 \\
7 \\
3 \\
6.5 \\
1 \\
4\end{array}$ & $\begin{array}{l}4 \\
2 \\
3 \\
0.5 \\
6 \\
0 \\
0.5 \\
8 \\
5.5 \\
1.5 \\
5 \\
2.5 \\
2.5 \\
1 \\
2.5\end{array}$ & $\begin{array}{l}-2 \\
-2 \\
-2 \\
3.5 \\
-1 \\
2.5 \\
3.5 \\
-2 \\
-1.5 \\
1.5 \\
2 \\
1.5 \\
4 \\
0 \\
1.5\end{array}$ \\
\hline
\end{tabular}

Table 4 Correlations between imaging modalities, including arthroscopic assessment, region of interest magnetic resonance analysis, and immunohistology

\begin{tabular}{lll}
\hline Correlations & rvalue & p value \\
\hline VAS and "Y" - SPP region & 0.774 & 0.003 \\
"Y" and CD4 & 0.7022 & 0.011 \\
VAS and CD4 & 0.5694 & $0.053^{\star}$ \\
VAS and hyperplasia - SPP region & 0.5924 & 0.042 \\
VAS and hyperplasia & 0.6952 & 0.012 \\
CD4 and hyperplasia & 0.6291 & 0.028 \\
\hline
\end{tabular}

Statistical significance at the 5\% level using Spearman's correlation. *Borderline statistically significant.

Four patients (three from the $40 \mathrm{mg}$ group and one placebo) experienced pain at the injection site on drug administration, no further sequelae were identified. One patient from each treatment group also experienced mild worsening of synovitis and swelling in the target knee, which resolved fully by the final study visit and did not require additional treatment.

\section{Discussion}

This double blind study showed that IA administration of SB-210396/CE 9.1, a primatised anti-CD4 MAb, at $40 \mathrm{mg}$ is safe and produces a trend toward improvement in MRI, arthroscopic, and histological outcome measures. Significant correlations were demonstrated between the three imaging modalities studied, all of which were carried out by independent observers blinded to the other results. This provides internal consistency and strong support for this approach as a means of studying the mode of action of drugs. Importantly, the correlation between histology and MRI was significant only with those ROIs that corresponded to the site from which the biopsy specimen was taken. This highlights the patchy nature of disease and emphasises the importance of coordinated imaging with direct visualisation of biopsy and MRI.

Arthroscopic synovitis VAS improved consistently in all patients receiving active treatment while two placebo patients showed deterioration. Improvements were small, however in two of three low dose group and four of seven high dose group patients it was $>20 \%$.

A reduction in the median SM LLH with histological assessment occurred in all patients receiving active treatment while in the placebo patients it increased. Additionally, the CD4 scores decreased in the high dose group and improved in two of three low dose group patients with deterioration in the placebo group. There are a number of possible explanations for this apparent reduction in the number of CD4+ cells, which may represent a reduction in $\mathrm{T}$ cells or macrophages, or both, including fewer cells entering the joint, prolonged coating of cells or increased clearance from the SM.

Time dependent change of MRI SI after intravenous administration of Gd-DPTA is influenced by the local tissue properties such as perfusion, extracellular fluid volume, and capillary permeability. Descriptive variables such as ME and MRE reflect a combination of physiological variables, however, ME depends mainly on local Gd-DPTA availability (perfusion and volume of extracellular fluid) whereas MRE reflects capillary permeability. ${ }^{30}$ Analysis of these DEMRI variables at both specific ROIs showed improvement in the high dose group compared with placebo in a dose response trend, although synovial volumes did not change significantly. This is in contrast with previous findings by Ostergaard et al, ${ }^{26}$ who showed a good correlation with measurement of total enhancing volume. In that work, regions were defined interactively introducing possible bias, additionally percentage enhancement was not calculated.

In addition to the changes within each imaging modality several strong correlations were observed between sequential same day DEMRI measures, arthroscopic VAS for synovitis, and synovial immunohistochemistry, specifically between MRE, synovitis VAS, and CD4 score. The validity of these correlations is supported by the fact that they were consistent at two separate time points-before and after treatment. Two previous studies attempted to correlate dynamic MR with SM histology ${ }^{18} 19$ showing correlation between synovial volume and inflammation. In a further study of anterior knee pain, some correlation between clinical, arthroscopic, and MRI features was described. ${ }^{22}$ Limitations of all these studies were long $\mathrm{MR}$ acquisition intervals and/or closed needle biopsy with mismatch to MR analysis and reduced sensitivity, furthermore in these studies, there was no immunohistochemical staining.

This is the first study to examine a therapeutic intervention simultaneously with arthroscopic assessment, histological assessment, and MRI. The dynamic MR sequences with high temporal resolution continuing into plateau phase, provides a more accurate measure of tissue microcirculation. In addition, the time lapse between MR scan and arthroscopy was minimal ( $<2$ hours) and SM biopsy specimens were obtained by direct visualisation. Previous intervention studies using SM examination as an outcome are limited, one study of gold treated patients ${ }^{31}$ correlated clinical improvement with reduced inflammatory cell infiltration. This study was limited by a high rate of failed biopsy, a problem overcome in this study by the use of arthroscopic SM sampling. 
Early studies of anti-CD4 treatment used murine, depleting $\mathrm{MAb}$ and subsequently chimeric, non-depleting MAbs. SB-210396/CE 9.1 is a chimeric primate/human MAb directed to surface expressed CD4. Phase II studies suggest it has good clinical efficacy when administered intravenously in patients with established RA. ${ }^{28}$ Intravenous SB-210396/CE 9.1 achieved good levels in the peripheral circulation and the side effect profile is good. The intra-articular concentration however may be sub-optimal, so this study looks at the question: is direct delivery of anti-CD4 MAb to the primary site of disease - the synovium-both safe and efficacious? Of 11 previous studies of IV anti-CD $4,{ }^{5-15}$ only one showed statistical clinical improvement and only three were blind and placebo controlled. Results have been disappointing considering the key putative role for CD4+ $T$ cells in RA and the dramatic clinical response with anti-TNF treatment, ${ }^{32}$ however the subjects had end stage disease and therefore less capacity for improvement. In contrast, the study of intravenous SB210396/CE 9.1 in established refractory RA showed that this MAb was efficacious. ${ }^{25}$ The study of intravenous chimeric murine/human antibody (cM-T412) in short disease duration patients $(<1.5$ years) showed little clinical benefit, ${ }^{13}$ but a decreased cellular infiltration and adhesion molecule expression after four weeks. In contrast, the study of anti-TNF MAb (cA2) resulted in clinical benefit and a reduction in SM cellularity but no correlation between the two. ${ }^{32}$

The management of resistant knee synovitis in RA remains a significant clinical problem. In the event of lack of efficacy of IA corticosteroids, alternative treatment options are limited. Manipulation of DMARD dose may not be possible because of toxicity, side effects and even if possible may result in marked delay in clinical response. This study shows that IA administration of SB-210396/CE 9.1 is safe and well tolerated by patients and it suggests possible efficacy of at least a dose of $40 \mathrm{mg}$ IA SB-210396/CE 9.1, (possibly at $0.4 \mathrm{mg}$ ), in RA patients with resistant knee synovitis. The regimen of combined imaging in assessing outcome using dynamic MRI, arthroscopy, and SM biopsy has demonstrated significant correlations in a number of parameters. This study confirms the feasibility and validity of a combined imaging approach, suggesting this is a useful method for mode of action studies for therapeutic agents in RA treatment. It is possible that it will also result in new therapeutic approach for locally resistant joints.

Funding: this work was supported by SmithKline Beecham Pharmaceuticals, New Frontiers Science Park (South), Third Avenue, Harlow, Essex, CM19 5AW, United Kingdom.

1 Panayi GS, Lanchbury JS, Kingsley GH. The importance of the $T$ cell in initiating and maintaining the chronic synovitis of rheumatoid arthritis. Arthritis Rheum 1992;35:72935 .

2 Paulus HE, Machleder HI, Levine S, Yu DT, MacDonald Paulus HE, Machleder HI, Levine S, Yu DT, MacDonald
NS. Lymphocyte involvment in rheumatoid arthritis. Studies during thoracic duct drainage. Arthritis Rheum 1977;20:1249-62.
3 Trentham DE, Belli JA, Anderson RJ, Buckley JA, Goetzl EJ, David JR, et al. Clinical and immunological effects of fractionated total lymphoid irradiation in refractory rheumatoid arthritis. N Engl J Med 1981;305:976-82.

4 Tugwell P, Pincus T, Yocum D, Stein M, Gluck O, Kraang G. Combination therapy with cyclosporine and methotrexate in severe rheumatoid arthritis. N Engl J Med 1995;333: 137-42.

5 Herzog C, Walker C, Muller W, Rieber P, Reiter C, Riethmuller G, et al. Anti-CD4 antibody treatment of patients with rheumatoid arthritis. I. Effect on clinical course and circulating T cells. J Autoimmun 1989;2:62742 .

6 Horneff G, Burmester GR, Emmrich F, Kalden JR Treatment of rheumatoid arthritis with an anti-CD4 monoclonal antibody. Arthritis Rheum 1991;34:129-40.

7 Reiter C, Kakavand B, Rieber EP, Schattenkirchner M, Riethmuller G, Kruger K. Treatment of rheumatoid arthritis with monoclonal CD4 antibody M-T151: clinical results and immunopharmacologic effects in an open study, including repeated administration. Arthritis Rheum 1991;34:525-36.

8 Goldberg D, Morel P, Chatenoud L, Boitard C, Joel Menkes $\mathrm{C}$, Bertoye $\mathrm{PH}$, et al. Immunological effects of high dose administration of anti-CD4 antibody in rheumatoid arthritis patients. J Autoimmun 1991;4:617-30.

9 Wendling D, Racadot E, Morel-Fourrier BJW. Treatment Wendling D, Racadot E, Morel-Fourrier BJW. Treatment
of rheumatoid arthritis with anti-CD4 monoclonal antibody: open study of 25 patients with the B-F5 clone. antibody: open study of 25 patient

10 Choy ES, Pitzalis C, Cauli A, Bijl JA, Schantz A, Woody J, et al. Percentage of anti-CD4 monoclonal antibody-coated lymphocytes in the rheumatoid joint is associated with clinical improvement: Implications for the development of immunotherapeutic dosing regimens. Arthritis Rheum 1996;39:52-6.

11 Van der Lubbe PA, Reiter C, Breedveld FC, Kruger K, Schattenkirchner M, Sanders ME, et al. Chimeric CD4 monoclonal antinody cM-T412 as a therapeutic approach
to rheumatoid arthritis. Arthritis Rheum 1993;36:1375-9.

12 Moreland LW, Bucy RP, Tilden A, Pratt PW, LoBuglio AF Khazaeli M, et al. Use of a chimeric monoclonal anti-CD4 Khazaeli $M$, et al. Use of a chimeric monoclonal anti-CD4
monoclonal antibody in patients with refractory rheumamonoclonal antibody in patients with refractory

13 Moreland LW, Pratt PW, Mayes MD, Postlethwaite A, Weisman MH, Schnitzer T, et al. Double blind, placebo controlled, muti-center trial using chimeric monoclona anti-CD4 antibody, cM-T412, in rheumatoid arthritis patients receiving concomitant methotrexate. Arthritis Rheum 1995;38:1581-8.

14 Van der Lubbe PA, Dijkmans BAC, Markusse HM, Nassander U, Breedveld FC. A randomised, double blind, placebo controlled study of CD4 monoclonal antibody therapy in early rheumatoid arthritis. Arthritis Rheum 1995;38:1097-106.

15 Choy EHS, Chikanza IC, Kingsley GH, Corrigall V, Panayi GS. Treatment of rheumatoid arthritis with single dose or weekly pulses of chimaeric anti-CD4 monoclonal antibody. Weand J Immunol 1992;36:291-8.

16 Tak PP, Van der Lubbe PA, Cauli A, Daha MR, Smeets TJM, Kluin PM, et al. Reduction of synovial inflammation after anti-CD4 monoconal antibody treatment in early rheumatoid arthritis. Arthritis Rheum 1995;38:1457-65.

17 Epstein WV. Expectation bias in rheumatoid arthritis clinical trials: The anti-CD4 monoclonal antibody experience. Arthritis Rheum 1996;39:1773-80.

18 Gaffney K, Cookson J, Blake D, Coumbe A, Blades S. Quantification of rheumatoid synovitis by magnetic resonance imaging. Arthritis Rheum 1995;38:1610-17.

19 Tamai K, Yamato M, Yamaguchi T, Ohno W. Dynamic magnetic resonance imaging for the evaluation of synovitis in patients with

20 Reece RJ, Emery P. Needle arthroscopy. Br J Rheumatol 1996;34:1102-4

21 Ike RW. Diagnostic arthroscopy. Baillieres Clin Rheumatol 1996;10:495-517

22 Foley-Nolan D, Stack JP, Ryan M, Redmond U, Barry C, Ennis J, et al. Magnetic resonance imaging in the assesment of rheumatoid arthritis - a comparison with plain film radiographs. Br J Rheumatol 1991;30:101-6.

23 Gilkeson G, Polisson R, Sinclair H. Early detection of carpal erosions in patients with rheumatoid arthritis: a pilot study with magnetic resonance imaging. J Rheumatol 1988;15: with ma $1361-6$.

24 Gramas DA, Antounlan FS, Peterfy CG, Genant HK, Lane NE. Assessment of needle arthroscopy, standard arthroscopy, physical examination and magnetic resonance imaging in knee pain: a pilot study. J Clin Rheumato 1996;1:26-34

25 Bjorkengren AG, Geborek P, Rydholm U, Holtas S, Petterson $\mathrm{H}$. Magnetic resonance imaging of the knee in acute rheumatoid arthritis: synovial uptake of gadoliniumDPTA. Am J Roentgenol 1990;155:329-32,

26 Ostergaard M, Stoltenberg M, Henriksen O, Lorenzen I. Quantiitative assessment of synovial inflammation by Quantitative assinm-entan by maging: A study of the effect of intra-articular methylprednisolone on the rate of early synovial enhancement. Br J Rheumatol 1996;35:50-9.

27 Konig H, Sieper J, Wolf KJ. Rheumatoid arthritis: evaluation of hypervascular and fibrous pannus with dynamic MR imaging enhanced with Gd-DPTA. Radiology 1990;176: $473-7$. 
28 Levy R, Weisman M, Weisenhutter C, Yocum D, Schnitzer $\mathrm{T}$, Goldman A, et al. Results of a placebo-controlled multicenter trial using a primatized non-depleting, anti-CD monoclonal antibody in the treatment of rheumatoid arthritis. [Abstract]. Arthritis Rheum 1996;39:574.

29 Robb RA, Hanson DP, Karwoski RA, Larson AG, Workman EL, Stacey MC. ANALYZE: A comprehensive, operatorinteractive software package for multidimensional medical image display and analysis. Comput Med Imaging Graph 1989;13:433-54.

30 Radjenovic A, Berry E, Ridgway JP, O’Connor P, Reece R, Gibbon WW, et al. Relationship between pharmacokinetic and black-box parameters in quantitiative analysis of dynamic Gd-DTPA enhanced MRI. Berkely: Internationa Society for Magnetic Resonance in Medicine 1997;330.

31 Yanni G, Nabil M, Farahat MR, Poston RN, Panayi GS Intramuscular gold decreases cytokine expression and macrophage numbers in the rheuamtoid synovial membrane. Ann Rheum Dis 1994;53:315-22.

32 Tak PP, Taylor PC, Breedveld FC, Smeets TJM, Daha MR, Kluin PM, et al. Decrease in cellularity and expression of adhesion molecules by anti-tumor necrosis factor a monoclonal antibody treatment in patients with rheumatoid arthritis. Arthritis Rheum 1996;39:1077-81.

\section{Historical images}

Series editors: W Grassi, C Cervini

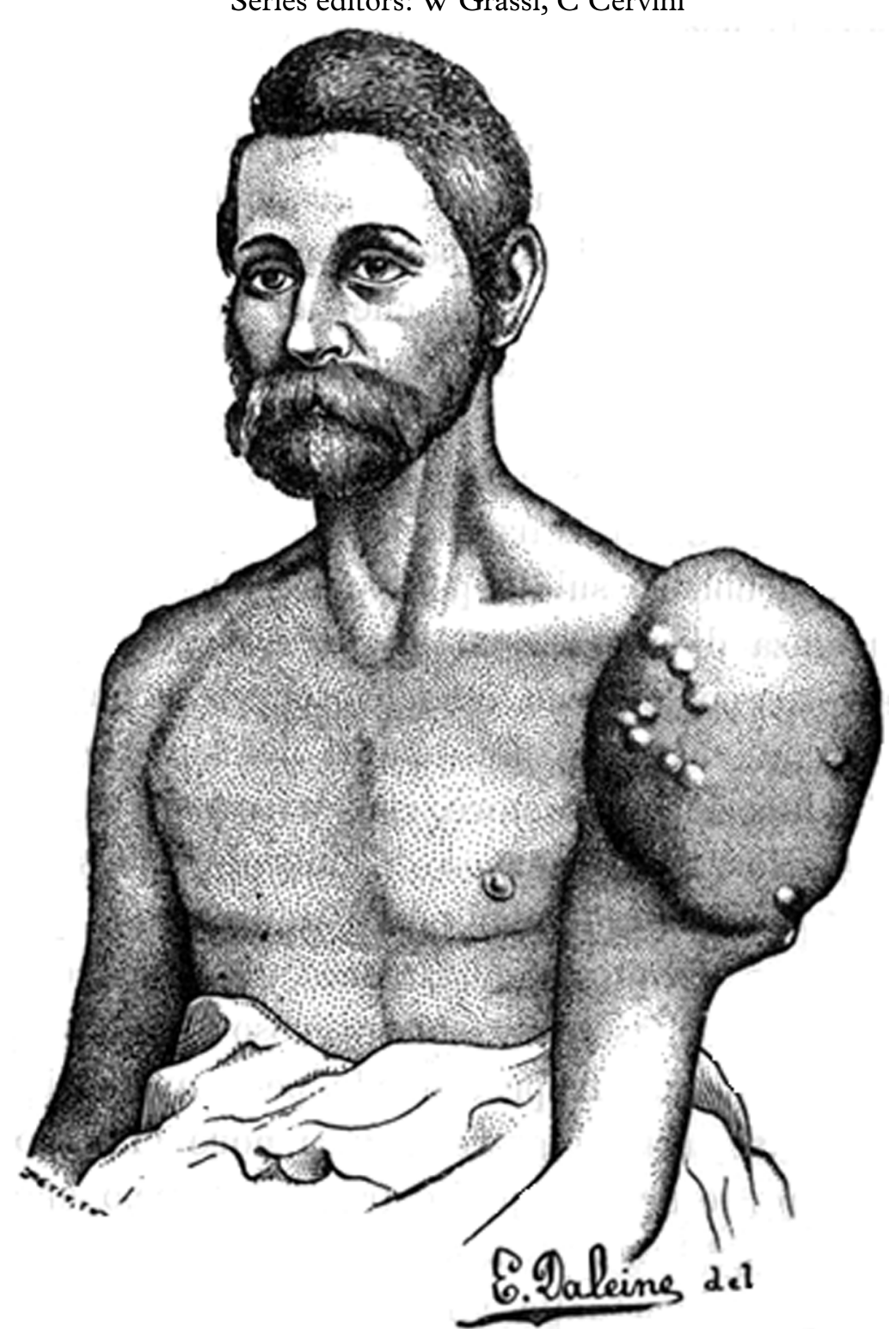

Figure 15 Enchondroma of the humerus.

Kirmisson. Malattie degli arti. In: Duplay S, Reclus P, eds. Trattato di chirurgia. Turin: Unione Tipografico Editrice, 1895. 